\title{
Past, present, and future of endovascular stroke therapies
}
M.A. Taqi, MD
N. Vora, MD
R.C. Callison, MD
R. Lin
T.J. Wolfe, MD

Correspondence \& reprint requests to Dr. Taqi mtaqi@mcw.edu Or Dr. Wolfe: twolfemd@yahoo.com

\section{ABSTRACT}

Endovascular therapy in the acute management of ischemic stroke has become more common with technologic advances, such as easier navigation into the intracranial circulation and improved treatment efficacy with the advent of revascularization devices. This select review outlines milestones in the application of endovascular therapy in acute ischemic stroke (AIS) and offers some insight into important factors influencing the future directions of endovascular AIS treatment. In particular, we discuss the evolution of endovascular devices for AIS and how ingenuity continues to offer novel treatments. With these advances, the future of endovascular AIS treatment is promising. Neurology ${ }^{\circledR} 2012 ; 79$ (Suppl 1):S213-S220

\section{GLOSSARY}

AIS = acute ischemic stroke; DAC $=$ distal access catheter; FDA = US Food and Drug Administration; HDE = humanitarian device exemption; IA = intra-arterial; IMS = Interventional Management of Stroke; IU = international units; MERCI = Mechanical Embolus Removal in Cerebral Ischemia; PMA = premarket approval; $\mathbf{S I C H}=$ symptomatic intracerebral hemorrhage; TIMI = thrombolysis in myocardial ischemia; tPA = tissue plasminogen activator.

The concept of interventional treatment of acute ischemic stroke (AIS) is analogous to the percutaneous treatment of acute myocardial infarction in that the occlusive lesion is accessed via the vascular system and recanalization is achieved with endovascular techniques. Such an approach has become a standard treatment for acute coronary syndromes but has not achieved widespread acceptance for AIS. This is in large part due to the limitations of a single US Food and Drug Administration (FDA)-approved treatment for AIS, narrow therapeutic windows for treatment, and an immature repertoire of endovascular tools available for the neurointerventionalist. However, over the last 16 years, since FDA approval of tissue plasminogen activator (tPA), the field of stroke neurology has bridged this gap with improved imaging techniques and clinical trial design to consider endovascular treatment. This has been coupled with better navigation into the intracranial circulation with a newer generation of cerebral-specific catheters, microwires, and, ultimately, reperfusion devices.

This review evaluates and discusses the different endovascular strategies for acute ischemic stroke treatment, including the evolution of each technique over the past decade. These strategies include the following:

1. Chemical local recanalization

2. Mechanical recanalization

3. Augmentation of collateral flow or reversal of flow

CHEMICAL LOCAL RECANALIZATION Early endovascular treatment of AIS was limited by the difficulty in achieving distal cranial access. Access into the proximal vessels (carotid and vertebral arteries) was possible, however, and medications were delivered here for thrombolysis of cerebral emboli. ${ }^{1,2}$ These preliminary reports suggested the possibility of a $75 \%$ rate of recanalization, though this was associated with $20 \%$ incidence of asymptomatic hemorrhagic conversion. In 1999, the Prolyse in Acute Cerebral Thromboembolism (PROACT) II study demonstrated safety and efficacy in the treatment of middle cerebral artery M1 and M2

From The Institute of Clinical Orthopedics and Neurosciences (M.A.T., T.J.W.), Desert Regional Medical Center, Palm Springs, CA; and Departments of Neurology, Neurosurgery, and Radiology (R.L.) and Departments of Neurology and Psychiatry (N.V., R.C.C.), St. Louis University, St. Louis, MO.

Go to Neurology.org for full disclosures. Disclosures deemed relevant by the authors, if any, are provided at the end of this article. 
occlusions within 6 hours, with use of an intraclot infusion of prourokinase vs systemic heparinization. ${ }^{3,4}$ Recanalization was $66 \%$ in the treatment arm, compared with $18 \%$ that did translate into better functional outcomes ( $40 \%$ vs $25 \%$ ). A similar study with some technical differences was reported from Japan before the approval of IV tPA. The study was performed with 114 patients within 6 hours of stroke onset; intra-arterial (IA) urokinase was used. The rate of partial recanalization was $74 \%$, whereas complete recanalization was only $5 \%$. The incidence of intracranial hemorrhage was $9 \% .5$

Prourokinase, which is no longer commercially available, was a second-generation plasminogen activator with high fibrin specificity, similar to alteplase. The next-generation thrombolytics reteplase and tenecteplase have higher plasmin specificity, and their use had been reported in small case series, but no randomized trials have been performed yet.

Desmoteplase is the newest generation of plasminogen activators and is the most potent and selective activator for fibrin-bound plasminogen. The Desmoteplase in Acute Ischemic Stroke (DIAS) trials I and II and the Dose Escalation of Desmoteplase in Acute Stroke (DEDAS) study demonstrated that a dose of up to $125 \mu \mathrm{g} / \mathrm{kg}$ had good recanalization rates, with lower risk of symptomatic intracerebral hemorrhage (SICH).$^{6-8}$ DIAS III is a larger randomized trial conducted in Europe that has been prematurely stopped, and the results are unavailable.

BB10153 is a modified plasminogen in which the plasminogen activator receptor is replaced by the thrombin receptor. This would result in plasminogen binding to fibrin and dissolving a clot, without a need for plasminogen activator. This study is still ongoing. Similar to BB10153, V10153 is a recombinant plasminogen that is activated by thrombin. The phase II study, VASST, was halted because of a high risk of hemorrhagic complications: $3 / 9$ (33\%) in a 7.5-mg dose arm. Further trials are planned to study safety of lower dosages.

Direct delivery of a drug through microcatheter has made it possible to use plasmin in its active form, potentially providing a stronger fibrinolytic action. A recently published study showed an in vivo comparison of plasmin and tPA for clot lysis and did not show any statistically significant difference. ${ }^{9}$ A phase II dose escalation therapy using $20 \mathrm{mg}, 40 \mathrm{mg}$, and $60 \mathrm{mg}$ is ongoing in Europe. Microplasmin is another type of plasmin which is resistant to the effects of antiplasmin. Animal studies have shown good recanalization rates without higher incidence of intracerebral hemorrhage. ${ }^{10}$ A phase II trial, MITI0IV, has shown promising result without increase in the risk of intracranial hemorrhage. The results were an- nounced at a world stroke conference but have not been published yet.

Alfimeprase is a fibrolase derivative, which is a zinc containing metalloendopeptidase, and was first isolated from snake venom. It is a direct fibrinolytic that does not require plasminogen to break the clot. This was tested in the Catheter Directed Alfimeprase for Restoration of Neurologic Function and Rapid Opening of Arteries in Stroke (CARNEROS) II trial and did not improve the revascularization endpoints, but full results have not been published.

Ancrod is a fibrinogen-depleting agent isolated from snake venom that has been studied for the treatment of acute stroke. A small randomized trial has shown it reduced the number of deaths without any significant changes in the rate of intracranial hemorrhage. A large randomized trial of 500 patients did not show any significant improvement in outcome, with a trend toward higher incidence of intracerebral hemorrhage. ${ }^{11}$

Adjunctive therapies with combination of thrombolytic medications with heparin and glycoprotein IIb/IIIa inhibitors have been tested in the past and are still under investigation in ongoing trials.

Adjunctive heparin. The use of heparin can potentially hasten the clot dissolution as well as prevent reocclusion, as fibrinolytic activity by thrombolytics creates a prothrombotic state. In one study, recanalization rates ( $81.8 \%$ vs $40 \%$ ) were significantly higher in patients with high-dose heparin $(100 \mathrm{IU} / \mathrm{kg}$ bolus followed by $1,000 \mathrm{IU} / \mathrm{h})$ vs low-dose heparin (2000 IU bolus followed by $500 \mathrm{IU} / \mathrm{h}$ ) but at the expense of higher rates of intracranial hemorrhage $(15.4 \%$ vs $7.1 \%$, respectively). ${ }^{2}$ The later protocol has been widely adapted and has been used in the ongoing Interventional Management of Stroke (IMS) III trial. $^{12}$

Adjunctive glycoprotein IIb/IIIa inhibitors. Use of glycoprotein IIb/IIIa inhibitors has been demonstrated in small nonrandomized trials. A larger randomized trial of 801 patients, AbSETT, was terminated prematurely. In this trial, 3 cohorts of patients were studied: patients with stroke onset $<5$ hours, 5 to 6 hours, and within 3 hours (wake-up strokes). No significant difference in good outcome was found in any of the cohorts. The wake-up stroke cohort did not have statistically significantly better outcomes in the placebo arm. Rates of symptomatic intracranial hemorrhages were significantly higher with abciximab than with placebo in all groups. ${ }^{13}$

Future of chemical thrombolysis. A newer generation of fibrinolytics has been developed that could have more potent effects, with more selectivity for the clot and less neurotoxicity. These agents need to be tested 
in large, randomized trials to advocate their use over traditional tPA. Also, most of these agents have been tested intravenously, and IA trials are needed.

Other classes of lytics, such as alfimeprase and fibrinogen-depleting agents, have not shown promising results when used IV. Use of IA plasmin can potentially have higher success rates of recanalization. The trial comparing microplasmin with tPA has shown some benefit over the latter.

Trials using combinations of IV tPA and glycoprotein IIb/IIIa inhibitors and a combination of IV and IA tPA are underway. CLEAR was a randomized doubleblind multicenter trial comparing standard-dose IV tPA vs a combination of $2 / 3 \mathrm{tPA}$ dose $(0.6 \mathrm{mg} / \mathrm{kg})$ plus eptifibatide bolus, $135 \mu \mathrm{g} / \mathrm{kg}$ and 2-hour infusion at 0.75 $\mu \mathrm{g} / \mathrm{kg} / \mathrm{min} .{ }^{14}$ The study is not fully published but showed a symptomatic hemorrhage rate of $1.4 \%$ in the group of patients that received the combined IV tPA and IV eptifibatide (69/94). No significant difference in good outcome was found.

IMS III is an ongoing trial, randomizing patients who present within 3 hours of symptom onset to either full-dose IV tPA $(0.9 \mathrm{mg} / \mathrm{kg}$; $\max , 90 \mathrm{mg})$ or a $2 / 3$ dose of IV tPA $(0.6 \mathrm{mg} / \mathrm{kg}$; total, $60 \mathrm{mg})$ with endovascular stroke treatment. The IA therapy is conducted in the presence of clot and could include IA tPA (up to $22 \mathrm{mg}$ ) and 1 mechanical approach: the Ekos, Merci, or Penumbra system, described in the next section. ${ }^{12}$

Even with advances in the mechanical thrombectomy device design, the relative ease of navigation through complex cerebrovascular anatomy of the microcatheter will remain an advantage for chemical lysis. The newer drugs and possible combinations of different therapies will shape the future of chemical lysis for acute stroke.

MECHANICAL RECANALIZATION The use of mechanical recanalization techniques has become common in the endovascular management of AIS. The main treatment strategies include thrombectomy, suctioning, or thrombus disruption.

Angioplasty. Angioplasty had been used in cardiac atherosclerotic disease since the 1960s for minimally invasive revascularization of the coronary circulation. ${ }^{15}$ Initial limitations to using early angioplasty balloons for AIS intervention were their size and poor tractability into the cerebral vasculature. As technology improved, access into the intracranial circulation became more feasible, offering a chance at acute recanalization upon balloon inflation. ${ }^{16} \mathrm{Lim}$ ited reports exist on the primary use of balloon maceration in AIS, though this technique is commonly considered part of the elective or urgent management of severe intracranial atherosclerotic stenosis.
Arterial dissection and rupture are the biggest risks with intracranial balloon maceration, especially in AIS, when often the occluded target vessel diameter cannot be fully quantified. In addition, with this technique the source of occlusion remains in situ, or it may be pushed into an adjacent patent branch, causing a new occlusion. However, a retrospective review showed that distal fragmentation of clot had no effect on long-term outcome. ${ }^{17}$

Stent placement. The first percutaneous endovascular stent was developed and tested in the 1980s. ${ }^{18}$ These relatively rigid balloon-mounted devices did not safely track into the cerebrovasculature. Later generations served as the basis for developing intracranial stents, as well as the use of shape-memory materials that allowed self-expanding design. This technology reconstructs the occluded vessel, reestablishing flow acutely, though with the potential dilemma of displacing occlusive material to the lumen's side. Retrospective reports have demonstrated efficacy of acutely deployed self-expanding stents for AIS, achieving $79 \%$ acute recanalization. ${ }^{19}$ Temporary partial deployment of a self-expanding stent followed by reconstrainment has been described with benefit on recanalization, without the actual implantation of the stent. ${ }^{20}$

Long-term safety of endoluminal implants is not fully understood. Also, their intravascular implantation necessitates the use of antithrombotic medications, which can increase the likelihood of hemorrhagic conversion of completed AIS.

Thrombectomy and mechanical thrombus dissolution. Devices designed for thrombectomy and thrombus dissolution may have an advantage over primary angioplasty for AIS, in that they help to reduce the burden of material at the site of proximal occlusion. Although many different device configurations have been described and tested, focus here will remain on the most widely used techniques.

FDA-approved intracranial clot retrievals. The Merci Concentric Retriever (Concentric Medical, Inc., Mountainview, CA) is the first FDA-approved (2004) embolectomy device for AIS. Three generations of Merci exist. The first generation (X5 and X6) contained a tapered nitinol coil loop. The second generation (L4, L5, and L6) added monofilaments on nontapered loops for better catchment of the clot. The third generation has variable pitch loops with monofilaments (V4, V5, and V6) and is available in soft and firm categories. The recommended system is a Merci balloon guide catheter with a $2.4 \mathrm{~F}$ delivery catheter and an optional 4.3F distal access catheter.

The Mechanical Embolus Removal in Cerebral Ischemia (MERCI) trial demonstrated a recanaliza- 
Figure 1 Penumbra catheters and separator (permission to use photograph granted by Penumbra)

Penumbra Catheters and Separators

Sizes

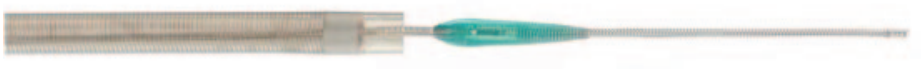

026

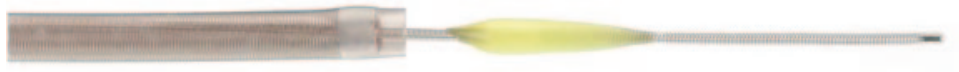

032

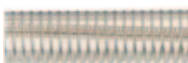

041

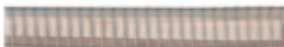

054

tion rate (thrombolysis in myocardial ischemia [TIMI] scores of 2 and 3 [TIMI2 and TIMI3]) of $46 \%$ by device alone and $60.8 \%$ by combination of the device and chemical thrombectomy. SICH occurred in $7.8 \%$ (X series). ${ }^{21}$ The Multi-MERCI trial further evaluated the safety efficacy of the firstgeneration device and collected safety and technical data for second-generation devices ( $\mathrm{X}$ and $\mathrm{L}$ series). The recanalization rates went up to $52 \%$ by device alone and $68 \%$ by device and tPA combination; SICH occurred in $9.8 \%$ of patients. These improvements were attributed to enhanced experience with using a device and modification in design. Because patients receiving IV tPA without recanalization were also included, this trial showed safety of Merci retrieval post-thrombolysis. ${ }^{22}$

Penumbra (Penumbra, Inc., Alameda, CA) is the other FDA-approved intracranial clot retrieval. This is a flexible catheter system connected to a vacuum pump, which suctions the thrombus into the catheter. A microwire-based separator then helps clear pieces of thrombus that could occlude the distal catheter. The pilot Penumbra trial included 20 patients, with excellent recanalization rates. The larger Penumbra stroke trial enrolled 125 patients, with an $81.6 \%$ rate of recanalization. Symptomatic hemorrhage occurred in $11.2 \%$.

With recent modifications, 4 sizes are available: $0.054,0.041,0.032$, and 0.026; these can be used according to the vessel size. Improvements to the aspiration capacity of the catheter, as well as modifications to improve the separator wire's efficiency, are underway. ${ }^{23}$

Figure 1 shows different sizes of Penumbra catheters and separators.

Other clot retrievers. Multiple other devices exist that are FDA-approved to remove a foreign body but not specifically from the brain. Use of these devices has been described in case reports and case series.

Neuronet (Guidant, Santa Clara, CA) is an FDAapproved body retrieval device with a nitinol basket. It is hard to navigate it around tortuous vessels, but it can be useful for straight vessels. Its efficacy in retrieving intracranial clots has been described in case reports and a small European trial (Neuronet Evaluation in Embolic Stroke Disease [NEED]). ${ }^{24}$

Catch (Balt; Montmorency, France) is a selfexpanding basket device that has been used for clot removal from the brain. A small animal study compared Catch with Merci and found them to be equally effective. ${ }^{25}$ Recent case series of patients showed a recanalization rate of $65 \%$, with SICH occurring in $18 \% .^{26}$

The Phoenix Clot Retriever (Phoenix GmbH, Bochum, Germany) is a brush-like retrieval device that is deployed into the clot with a 0.021 or 0.027 microcatheter. It has a flexible nitinol/platinum alloy wire with polyamide monofilament radiating outwards. Initial case studies showed it was safe and effective, but it was never tested in a large randomized trial. The newly modified Phoenix clot retriever cage version has a small cage at the proximal end of the brush. Animal model success was recently published, showing a complete recanalization rate of $86.7 \%$ in 15 studied vessels. In a recently treated group of 48 patients, the reported recanalization rate was $56.3 \% .^{27,28}$

The Alligator Retrieval Device (Chestnut Medical, Menlo Park, CA) has been approved by the FDA for endovascular removal of foreign bodies and has been used to remove intracranial clots. ${ }^{29}$

Similarly, TriSpan (Boston Scientific, Natick, MA) and EnSnare (Merit Medical, Salt Lake City, UT) are not FDA-approved devices for clot removal, but off-label use has been reported. TriSpan is no longer marketed in the United States.

The AngioJet system (Possis Medical, MN) is a thrombo-aspiration device that creates distal Venturi suction from a pulsed high-pressured saline jet. It has been successfully used for peripheral and coronary clots, but because of the lack of ability to track in brain vessels, its use is limited. ${ }^{30}$

Alternative strategies for delivering energy to the site of intracranial thrombus are suggested to facilitate thrombolysis and thrombus disintegration. The Ekos MicroLysUS catheter (EKOS Corp., Bothell, WA) provides ultrasound adjunctively to systemic pharmacologic thrombolysis. Preliminary data suggest approximately $80 \%$ recanalization in less than 1 hour; further evaluation is pending as part of the IMS III trial. ${ }^{31}$ Others have attempted to dispose laser energy at the site of intracranial occlusion, but 
that has been taken out of US markets. ${ }^{32}$ Along with the size-related limiting of these applications for AIS, the impartation of heat energy may be deleterious.

Future of mechanical devices. Stent retrievers. The use of stent technology has been described in the history of endovascular treatment of stroke. Although mostly successful, it commonly comes with a problem of lack of antiplatelet activity at the time of stent deployment. The loading doses and maintenance of antiplatelet medications increase the risk for intracranial hemorrhage. With the advent of a closed-celldesign stent (Enterprise; Cordis Neurovascular, Miami, FL), it became possible to deploy the stent and resheath it, allowing temporary bypass and thrombectomy at the same time. Several case reports demonstrated the success and safety of this technique, but the possibility of unintentional deployment existed. Also, it was not possible to retrieve the stent into the guide catheter without resheathing it, which could result in clot embolization from the mouth of the microcatheter.

The first stent retriever device (Trevo; Concentric Medical) was launched in October 2010 in Europe. After animal trials, small trials in humans, and regulatory approval in Canada and Europe, the first patient was enrolled in the United States for the TREVO 2 trial in February 2011. The device consists of a stent mounted on the distal end of a microwire.

Trevo has a $10-\mathrm{mm}$ proximal tapered end, a 4- $\mathrm{mm}$ radiopaque distal wire, and a 6- $\mathrm{mm}$ distal tapered end. The stent can be delivered by Trevo 18 or any microcatheter with an inner diameter of 0.21 or greater. The outward radial force varies with the size

Figure 2 Old retrieval device, Merci, and a new stent retrieval device, Trevo (permission to use photographs granted by Stryker)

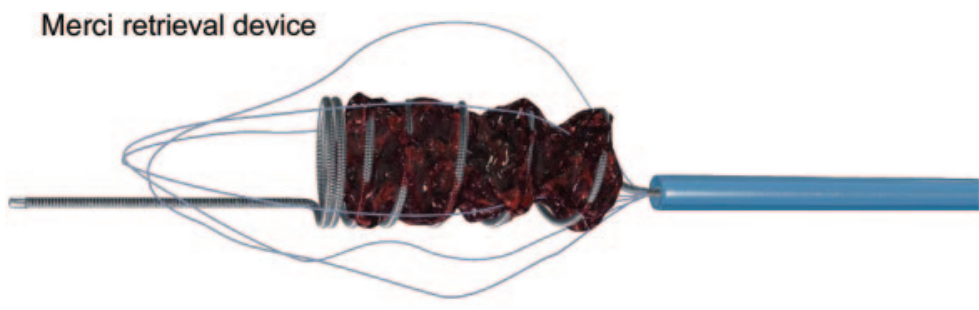

Trevo (stent retrieval device)

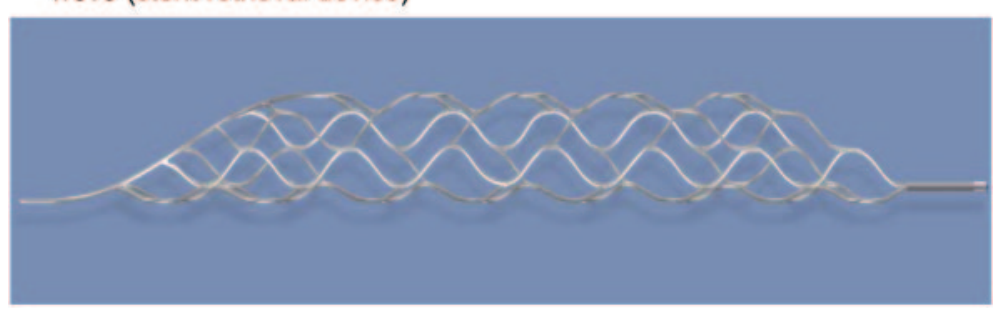

of the vessel. The stent can be retrieved into a 0.044 " DAC (distal access catheter) or 0.057" DAC.

A similar device, Solitaire (EV3, Irvine, CA), has already been studied in the United States, in the SWIFT trial. SWIFT compared the recanalization and outcomes in acute stroke after treatment by Solitaire vs Merci. The trial was stopped prematurely because of a trend toward significantly greater recanalization rates with Solitaire. Both Trevo and Solitaire are now FDA approved for intracranial clot retrieval.

The 4-mm device can be delivered through a 0.021 microcatheter, whereas the $6-\mathrm{mm}$ device requires a 0.027 microcatheter. Various case reports and case series have shown promising results. In a pilot study of 10 patients, the reported recanalization rates and good outcome, as defined by modified Rankin Scale scores of 0 to 2, were $90 \%$ and $45 \%$, respectively. The recanalization rates are highest among the previously reported trials with older devices. The rate of SICH was $10 \% .{ }^{33}$ Similar recanalization rates (95.4\%; thrombolysis in cerebral infarction 2) and good outcome (50\%) at 90 days were reported in another, 22-patient case series, ${ }^{34}$ and $100 \%$ partial recanalization was reported in a group of 11 patients treated in Austria. ${ }^{35}$ Brekenfeld et al. ${ }^{36}$ recently showed that the time to recanalization improved significantly (52.2 minutes vs 90 minutes) in the group of multimodality endovascular approach with Solitaire vs without Solitaire.

Figure 2 shows an old retrieval device, the Merci, and a new stent retrieval device, the Trevo.

Other future thrombectomy devices. Development of microwire- and microcatheter-based electromagnetic technology will allow sublocalization and concentration of systemically administered medicated particles at the site of distally oriented thrombi; this technology may additionally deliver focal energy similar to the Ekos catheter and laser-based devices, without generating deleterious heat. A modification of the separator for Penumbra was underway at the time this article was written and will soon be released. This will consist of multiple loops and wires that would break the clot and make it more amenable for suctioning. Modifications to other device designs being used currently will continue to improve ability to navigate and, at the same time, provide more efficient thrombectomy.

COLLATERAL REPERFUSION A novel approach to improving collateral flow in AIS is augmenting cerebral perfusion. The NeuroFlo balloon catheter (CoAxia, Inc., Maple Grove, MN) is an endovascular device designed to provide partial occlusion of the descending aorta, imparting flow diversion of cir- 


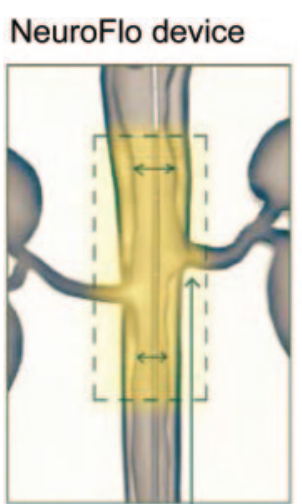

1.

Location of renals and diameter of aorta determined via simple aortogram

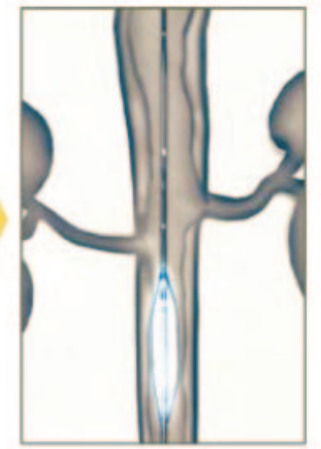

2.

NeuroFlo inserted to proper depth and infrarenal balloon inflated to reduce luminal area by $70 \%$

culating blood to the cerebral vasculature and improvement in cerebral perfusion. ${ }^{37}$ Preliminary data suggest a sustained improvement in cerebral perfusion in areas of infarction and surrounding penumbra. A phase III prospective, randomized trial is recently reported and showed no difference in the primary study endpoint of good recovery at 90 days between the Neuroflo group and control cohort. ${ }^{38}$ The study did meet the safety endpoint. A Neuroflo catheter with a larger inner lumen is being developed, to allow concurrent IA intervention in the more proximal cerebral vasculature.

Figure 3 shows the details of the Neuroflo system.

\begin{tabular}{|c|c|c|}
\hline $\begin{array}{l}\text { The } m \\
\text { acute }\end{array}$ & \multicolumn{2}{|c|}{$\begin{array}{l}\text { The most common devices available for mechanical thrombectomy in } \\
\text { acute ischemic stroke }\end{array}$} \\
\hline Devices & Company & FDA indication \\
\hline Merci & $\begin{array}{l}\text { Concentric } \\
\text { (now Stryker) }\end{array}$ & Restore neurovascular flow \\
\hline Penumbra & Penumbra, Inc. & Revascularization for acute stroke \\
\hline Neuronet & Boston Scientific & No longer marketed \\
\hline Catch & Guidant & Not marketed in United States \\
\hline $\begin{array}{l}\text { Phoenix clot } \\
\text { retrieval }\end{array}$ & Phoenix GmbH & Not marketed in United States \\
\hline Alligator & $\begin{array}{l}\text { Chestnut Medical } \\
\text { Technologies }\end{array}$ & $\begin{array}{l}\text { Foreign body from peripheral and } \\
\text { neural vasculature }\end{array}$ \\
\hline EnSnare & $\begin{array}{l}\text { Merit Medical } \\
\text { System, Inc. }\end{array}$ & $\begin{array}{l}\text { Retrieval of foreign object in cardiac } \\
\text { circulation or hollow viscous }\end{array}$ \\
\hline Ekos & EKOS Corporation & Infusion of fluid in peripheral vasculature \\
\hline Angiojet/Neurojet & Possis & No longer marketed \\
\hline Solitaire & EV3 & Approved for intracranial clot removal \\
\hline Trevo & $\begin{array}{l}\text { Concentric } \\
\text { (now Stryker) }\end{array}$ & Approved for intracranial clot removal \\
\hline
\end{tabular}

Abbreviation: FDA = US Food and Drug Administration.

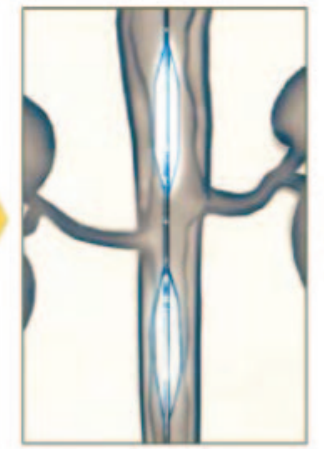

3.

Suprarenal balloon inflated to reduce luminal area by $70 \%$ : balloons remain inflated for 45 minutes

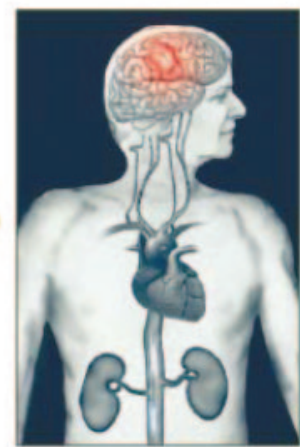

4.

Perfusion of the ischemic penumbra region is increased
Flow reversal. This is only experimental and has not been tested in humans. Revive Flow is the device under investigation. It requires placement of 2 balloon catheters, 1 on the arterial side and the other on the venous side. The catheters are connected to the reversal and pumping units. With inflation of the balloons, the circulation can be totally reversed to venous-arterial flow and perfuse the capillary bed distal to the clot, which then becomes proximal.

Theoretically, the retrograde flow through the region of arterial thrombus could facilitate dissolution or disruption, leading to concurrent thrombectomy. ${ }^{39}$

DISCUSSION AIS can be due to multiple etiologies, which may not be readily discerned acutely on presentation to the hospital; pathology of large and small arteries or veins and metabolic derangements can be implicated; and endovascular treatment may benefit only large to medium artery processes. The table demonstrates the most common devices available today for mechanical thrombectomy in AIS; many devices are being tested at the bench and in AIS models, which may be available in the future.

The regulatory process for bringing a device from preclinical testing to daily practice can be significant, and the FDA has several pathways for evaluating new technology. The $510(\mathrm{k})$ process, or premarket notification, allows a relatively more simple approval of new devices due to their substantial equivalence in safety and efficacy to another previously approved and marketed device. Premarket approval (PMA) is necessary when the device cannot fulfill the substantially equivalent comparison and poses risk to the patient. Investigational device exemption can allow initial approval for the sake of obtaining clinical data 
on safety and efficacy to support pursuit of a $510(\mathrm{k})$ or PMA. Humanitarian device exemption (HDE) is granted when a device is used for a specific condition in fewer than 4,000 individuals annually in the United States at centers with an institutional review board. HDEs are exempt from requirements to demonstrate effectiveness but must pose no unreasonable risks, or at least the probable benefits should outweigh the risks. At the time of $510(\mathrm{k})$, PMA, or HDE approval, the FDA can stipulate the requirement of postmarket studies.

The approval of multiple devices has added a challenge to the completion of multicenter trials such as IMS III.

There are several important factors for the success of an endovascular device in treating AIS. Success requires a balance of treatment by optimizing the SET triad of Safety, Efficacy, and Technical feasibility, or ease of use to allow rapid application. As new devices emerge and the treatment strategies become more refined, further improvement in efficacy can be seen for endovascular therapy for AIS. Safety will constantly be monitored as new devices are brought to the market and tested for efficacy in AIS. Only the devices that allow for easy application, with proven benefit on morbidity and mortality, will endure as part of the arsenal for the endovascular management of AIS.

\section{AUTHOR CONTRIBUTIONS}

Each author participated in writing and editing the manuscript.

\section{DISCLOSURE}

Dr. Taqi, Dr. Vora, and Dr. Callison report no disclosures. Dr. Wolfe holds a patent for a wire shaping device and catheter support system. Go to Neurology.org for full disclosures.

Received October 21, 2011. Accepted in final form January 17, 2012.

\section{REFERENCES}

1. Del Zoppo GJ, Ferbert A, Otis S, et al. Local intra-arterial fibrinolytic therapy in acute carotid territory stroke: a pilot study. Stroke 1988;19:307-313.

2. Zeumer H, Hacke W, Ringelstein EB. Local intraarterial thrombolysis in vertebrobasilar thromboembolic disease. AJNR Am J Neuroradiol 1983;4:401-404.

3. Del Zoppo GJ, Higashida RT, Furlan AJ, Pessin MS, Rowley HA, Gent M. PROACT: a phase II randomized trial of recombinant pro-urokinase by direct arterial delivery in acute middle cerebral artery stroke: PROACT investigators: Prolyse in Acute Cerebral Thromboembolism. Stroke 1998;29:4-11.

4. Furlan A, Higashida R, Wechsler L, et al. Intra-arterial prourokinase for acute ischemic stroke: the PROACT II study: a randomized controlled trial: Prolyse in Acute Cerebral Thromboembolism. JAMA 1999;282:2003-2011.

5. Ogawa A, Mori E, Minematsu K, et al. Randomized trial of intraarterial infusion of urokinase within 6 hours of middle cerebral artery stroke: the Middle Cerebral Artery
Embolism Local Fibrinolytic Intervention Trial (MELT) Japan. Stroke 2007;38:2633-2639.

6. Furlan AJ, Eyding D, Albers GW, et al. Dose Escalation of Desmoteplase for Acute Ischemic Stroke (DEDAS): evidence of safety and efficacy 3 to 9 hours after stroke onset. Stroke 2006;37:1227-1231.

7. Hacke W, Albers G, Al-Rawi Y, et al. The Desmoteplase in Acute Ischemic Stroke trial (DIAS): a phase II MRI-based 9-hour window acute stroke thrombolysis trial with intravenous desmoteplase. Stroke 2005;36:66-73.

8. Liebeskind DS. Reversing stroke in the 2010s: lessons from Desmoteplase in Acute Ischemic Stroke-2 (DIAS-2). Stroke 2009; 40:3156-3158.

9. Marder VJ, Blinc A, Gruber T et al. Comparison of plasmin with recombinant tissue-type plasminogen activator in lysis of cerebral thromboemboli retrieved from patients with acute ischemic stroke. Stroke 2011;42:2222-2228.

10. Thijs VN, Peeters A, Vosko $M$ et al. Randomized, placebo-controlled, dose-ranging clinical trial of intravenous microplasmin in patients with acute ischemic stroke. Stroke 2009; 40:3789-3795.

11. The Ancrod Stroke Study Investigators. Ancrod for the treatment of acute ischemic brain infarction. Stroke 1994; 25:1755-1759.

12. Khatri P, Hill MD, Palesch YY, et al. Methodology of the Interventional Management of Stroke III trial. Int J Stroke 2008;3:130-137.

13. Adams HP Jr, Effron MB, Torner J, et al. Emergency administration of abciximab for treatment of patients with acute ischemic stroke: results of an international phase III trial: Abciximab in Emergency Treatment of Stroke Trial (AbESTT-II). Stroke 2008;39:87-99.

14. Pancioli AM, Broderick J, Brott T, et al. The combined approach to lysis utilizing eptifibatide and rt-PA in acute ischemic stroke: the CLEAR stroke trial. Stroke 2008;39: $3268-3276$

15. Dotter CT, Judkins MP. Transluminal treatment of arteriosclerotic obstruction. description of a new technic and a preliminary report of its application. Circulation 1964;30: 654-670.

16. Tsai FY, Berberian B, Matovich V, Lavin M, Alfieri K. Percutaneous transluminal angioplasty adjunct to thrombolysis for acute middle cerebral artery rethrombosis. AJNR Am J Neuroradiol 1994;15:1823-1829.

17. Janjua N, Alkawi A, Suri MF, Qureshi AI. Impact of arterial reocclusion and distal fragmentation during thrombolysis among patients with acute ischemic stroke. AJNR Am J Neuroradiol 2008;29:253-258.

18. Wright KC, Wallace S, Charnsangavej C, Carrasco $\mathrm{CH}$, Gianturco C. Percutaneous endovascular stents: an experimental evaluation. Radiology 1985;156:69-72.

19. Levy EI, Mehta R, Gupta R, et al. Self-expanding stents for recanalization of acute cerebrovascular occlusions. AJNR Am J Neuroradiol 2007;28:816-822.

20. Kelly ME, Furlan AJ, Fiorella D. Recanalization of an acute middle cerebral artery occlusion using a selfexpanding, reconstrainable, intracranial microstent as a temporary endovascular bypass. Stroke 2008;39:17701773.

21. Smith WS, Sung G, Starkman S, et al. Safety and efficacy of mechanical embolectomy in acute ischemic stroke: results of the MERCI trial. Stroke 2005;36:1432-1438. 
22. Smith WS, Sung G, Saver J, et al. Mechanical thrombectomy for acute ischemic stroke: final results of the multi MERCI trial. Stroke 2008;39:1205-1212.

23. Penumbra Pivotal Stroke Trial Investigators. The penumbra pivotal stroke trial: safety and effectiveness of a new generation of mechanical devices for clot removal in intracranial large vessel occlusive disease. Stroke 2009;40:2761-2768.

24. Fussell D, Schumacher HC, Meyers PM, Higashida RT. Mechanical interventions to treat acute stroke. Curr Neurol Neurosci Rep 2007;7:21-27.

25. Brekenfeld C, Schroth G, El-Koussy M, et al. Mechanical thromboembolectomy for acute ischemic stroke: comparison of the Catch thrombectomy device and the Merci retriever in vivo. Stroke 2008;39:1213-1219.

26. Mourand I, Brunel H, Costalat V, et al. Mechanical thrombectomy in acute ischemic stroke: Catch device. AJNR Am J Neuroradiol 2011;32:1381-1385.

27. Henkes H, Reinartz J, Lowens S, et al. A device for fast mechanical clot retrieval from intracranial arteries (phenox clot retriever). Neurocrit Care 2006;5:134-140.

28. Mordasini P, Hiller M, Brekenfeld C, et al. In vivo evaluation of the phenox CRC mechanical thrombectomy device in a swine model of acute vessel occlusion. AJNR Am J Neuroradiol 2010;31:972-978.

29. Kerber CW, Wanke I, Bernard Jr, Woo HH, Liu MW, Nelson PK. Rapid intracranial clot removal with a new device: the alligator retriever. AJNR Am J Neuroradiol 2007;28:860-863.

30. Bellon RJ, Putman CM, Budzik RF, Pergolizzi RS, Reinking GF, Norbash AM. Rheolytic thrombectomy of the occluded internal carotid artery in the setting of acute ischemic stroke. AJNR Am J Neuroradiol 2001;22:526530 .
31. Mahon BR, Nesbit GM, Barnwell SL, et al. North American clinical experience with the Ekos MicroLysUS infusion catheter for the treatment of embolic stroke. AJNR Am J Neuroradiol 2003;24:534-538.

32. Berlis A, Lutsep $H$, Barnwell $S$, et al. Mechanical thrombolysis in acute ischemic stroke with endovascular photoacoustic recanalization. Stroke 2004;35:11121116.

33. Castano C, Dorado L, Guerrero C, et al. Mechanical thrombectomy with the solitaire $\mathrm{AB}$ device in large artery occlusions of the anterior circulation: a pilot study. Stroke 2010;41:1836-1840.

34. Roth C, Papanagiotou P, Behnke S, et al. Stent-assisted mechanical recanalization for treatment of acute intracerebral artery occlusions. Stroke 2010;41:2559-2567.

35. Wehrschuetz M, Wehrschuetz E, Augustin M, Niederkorn K, Deutschmann H, Ebner F. Early single center experience with the solitaire thrombectomy device for the treatment of acute ischemic stroke. Interv Neuroradiol 2011; 17:235-240.

36. Brekenfeld C, Schroth G, Mordasini P, et al. Impact of retrievable stents on acute ischemic stroke treatment. AJNR Am J Neuroradiol 2011;32:1269-1273.

37. Liebeskind DS. Aortic occlusion for cerebral ischemia: from theory to practice. Curr Cardiol Rep 2008;10: 31-36.

38. Shuaib A, Bornstein NM, Diener HC, et al. Partial aortic occlusion for cerebral perfusion augmentation: safety and efficacy of NeuroFlo in acute ischemic stroke trial. Stroke 2011;42:1680-1690.

39. Nogueira RG, Schwamm LH, Hirsch JA. Endovascular approaches to acute stroke, part 1: drugs, devices, and data. AJNR Am J Neuroradiol 2009;30:649-661. 


\section{Neurology}

\section{Past, present, and future of endovascular stroke therapies \\ M.A. Taqi, N. Vora, R.C. Callison, et al. \\ Neurology 2012;79;S213-S220 \\ DOI 10.1212/WNL.0b013e31826959e5}

This information is current as of September 24, 2012

\section{Updated Information \& \\ Services}

References

Subspecialty Collections

Permissions \& Licensing

Reprints including high resolution figures, can be found at:

http://n.neurology.org/content/79/13_Supplement_1/S213.full

This article cites 39 articles, 29 of which you can access for free at: http://n.neurology.org/content/79/13_Supplement_1/S213.full\#ref-list1

This article, along with others on similar topics, appears in the following collection(s):

\section{All Cerebrovascular disease/Stroke}

http://n.neurology.org/cgi/collection/all_cerebrovascular_disease_strok e

\section{Embolism}

http://n.neurology.org/cgi/collection/embolism

Infarction

http://n.neurology.org/cgi/collection/infarction

Intracerebral hemorrhage

http://n.neurology.org/cgi/collection/intracerebral_hemorrhage

Information about reproducing this article in parts (figures,tables) or in its entirety can be found online at:

http://www.neurology.org/about/about_the_journal\#permissions

Information about ordering reprints can be found online:

http://n.neurology.org/subscribers/advertise

Neurology ${ }^{\circledR}$ is the official journal of the American Academy of Neurology. Published continuously since 1951, it is now a weekly with 48 issues per year. Copyright Copyright (? 2012 by AAN Enterprises, Inc.. All rights reserved. Print ISSN: 0028-3878. Online ISSN: 1526-632X.

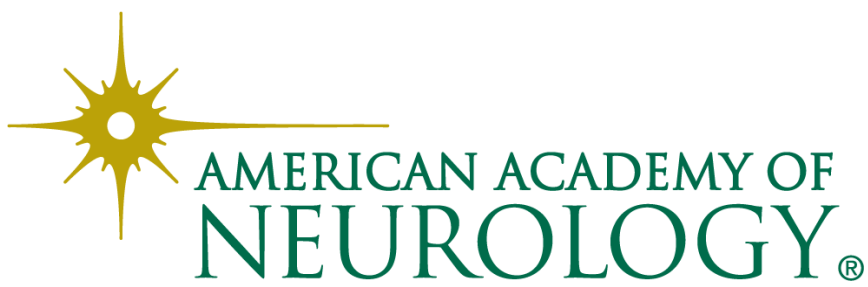

